\title{
Paperless handover: are we ready?
}

\author{
Arpana R Vidyarthi, ${ }^{1}$ Maitreya Coffey ${ }^{2}$
}

\begin{abstract}
${ }^{1}$ Education and Health Systems and Services Research, DukeNUS Graduate Medical School, Singapore, Singapore

${ }^{2}$ Centre for Quality Improvement and Patient Safety, University of Toronto, Toronto, Ontario, Canada
\end{abstract}

\section{Correspondence to} Dr Arpana R Vidyarthi, Education and Health Systems and Services Research, DukeNUS Graduate Medical School, 8 College Road, Singapore 169857, Singapore; arpana. vidyarthi@duke-nus.edu.sg

Accepted 9 November 2015 Published Online First 27 November 2015

\section{SLinked}

- http://dx.doi.org/10.1136/ bmjqs-2015-004585

\section{CrossMark}

$$
\begin{aligned}
& \text { To cite: Vidyarthi AR, } \\
& \text { Coffey M. BMJ Qual Saf } \\
& \text { 2016;25:299-301. }
\end{aligned}
$$

Scribbling patient information into the margins of pieces of paper during handover is a time-honoured tradition. House staff carefully guard these lists in pockets of white coats, on clipboards, or tucked into shoulder bags. They pull them out once the beeper goes off or mobile phone rings, and peer at the trusted information on the crumpled paper to guide their decision-making. 'Patient So-and-So has a fever', a nurse pages to inform the resident on-call, 'Can we give something for the fever? Do you want any blood work?' Other patients have confusion, pain or changes in their urine output. House staff record these events in check boxes, lines and circles, and read this back through bleary eyes to the incoming morning team.

The scene describes a common experience for house staff using handover documents. Given the non-standardised formats and often idiosyncratic forms of documentation, it has come as no surprise that handover, (also known as handoff, sign-out, passoff or transfer of accountability) represents a common source of communication failures. ${ }^{1}$ As such, regulating bodies now mandate using structured handover processes and the teaching of handover competencies. ${ }^{2} 3$ Over the past decade, a substantial body of research has informed our understanding of handover processes and quality, and a recent focused effort to improve handovers produced significant reductions in preventable patient harm. ${ }^{4}$ Notwithstanding these recommendations, the ritual of printing the handover document persists.

In an analysis of the use of the printed handover document at a major academic medical centre, Rosenbluth et $a l^{5}$ examined its 'half-life', defined as the time at which half of the patients on the list would be expected to have inaccurate information present. They found that the half-life is remarkably short: only $3 \mathrm{~h}$ during the day and $6 \mathrm{~h}$ overnight. Their approach is novel and accessible, as they applied a familiar concept ('half-life') to a new element of patient care. Their message is clear: in today's world of advanced information technology (IT), the printed handover document has lost its utility. But beneath this simple clarity lies substantial complexity, necessitating deeper consideration of current handover processes, the realities of today's hospitalbased care delivery and a vision of a way forward.

The handover document has evolved over time. Once taking the form of dozens of index cards hole-punched on a metal ring, it progressed to a manually updated simple stand-alone document on a shared drive. Today, many hospitals use electronic templates fully integrated into the electronic health record (EHR). Many of these electronic handover documents auto-import information and are available at all computer work-stations. This electronic handover progress has improved rounding efficiency and-in some institutions, at least-probably reduced medical errors. ${ }^{6-9}$ However, despite these advances and the explosion in clinical computing and handheld device usage, the practice of printing the handover document remains.

Rosenbluth et al reveal the challenges posed when relying on the static information on the printed handover document. These are germane, but in order to understand the reliance on paper, we need to fully appreciate the purposes of the document. Originally, the handover document was described as a place for key information required for patient care during periods of cross-coverage, ${ }^{10}$ but its purpose has changed over time. At its most basic, the handover document is a map, displaying who our patients are and where they can be found. It is also a work-flow manager, where key tasks are written and crossed off continuously throughout the day and night. In many situations, the handover document is considered the most succinct place to locate patient information. In an era of copy and paste, ${ }^{11}$ progress notes can become long, complicated and plagued by stale 
information. Furthermore, problem lists may translate well to DRGs (diagnosis-related groups) for coding or billing purposes, but lack the ability to effectively convey the patient's condition (eg, use of the term 'acute blood loss anaemia' in lieu of the more traditionally understood term of 'upper gastrointestinal bleeding'). With the handover note being considered the best place for synthesised and relevant information, many non-physician providers, including those at our institutions, are using it to inform their care delivery.

It is also a tool used for team communication. The approach to care for hospitalised patients has changed dramatically and rapidly over the last decade shifting from individual to team accountability. The tools to support these changes have not kept up. Thus, the handover document has attempted imperfectly to fill this gap. In the past, individual physicians were responsible and accountable for a relatively small number of patients who they knew well during their long hospital stay. In today's hospitals, teams of physicians with varying expertise collectively care for a larger number of very complex patients in a much shorter period of time. Given competing priorities of formal lectures and duty hour regulations, the 'primary doctor' may be responsible for a given patient for less than $50 \%$ of his/her hospitalisation. In addition, physicians are now required to work interdependently, as opposed to in parallel, with nurses, therapists and consultants of varying specialties to deliver effective and efficient care. Hospital-based healthcare teams are constantly shifting, formed and dissolved every $12 \mathrm{~h}$, and individuals on those teams consume and create information at different times and from disparate locations. The handover document attempts to assist in team communication, but the dynamic state of today's hospital teams limits its effectiveness in playing this role. One could imagine an electronic tool with the sole purpose of supporting team communication. This tool might be written collectively, and continuously retrieved, viewed and updated electronically in real-time. Such a tool might better serve the role of team communication that the handover document currently strives to play.

The authors advocate for relying on the EHR, as opposed to the static, rapidly inaccurate printed handover document to make decisions. This suggestion makes sense in principle, but may not support the practical reality of current healthcare environments. Given the multiple functions of the handover document, printing the document makes sense given the current state of most hospital IT systems. Most medical staff and trainees do not carry hospitalsupplied integrated mobile devices. Phones may be too small to be useful, while tablets and laptops are felt too large to be relevantly portable. Computers-on-wheels suffer from clunkiness and spotty wireless internet coverage. Even in rare circumstances where an EHR-based handover tool is well-formatted for a mobile device to which all staff have access, the number of clicks required to access specific fields and the slow processing speed renders the constant referencing, note-taking, and task checkoffs impossible. In these environments, paper makes these tasks possible.

At Singapore General Hospital, we can catch a glimpse of what a paperless delivery system looks like. House staff carrying portable laptops with arm straps and a few pieces of paper can be seen. The EHR requires minimal clicks, and the fast and ubiquitous wireless access supports its activities. This system is not without issues, some of which include laptops weighing $1.5 \mathrm{~kg}$, initial login time of $30-45 \mathrm{~s}$, and multiple users inputting orders from each device. The uptake of this system, though, is complete. These house staff grew up in the information age. They are accustomed to reading on a screen as opposed to the little clinical manuals and books that weighed down the pockets of house staff of the past. They are not accustomed to paper; therefore, they do not consider a paper-based solution for the imperfections of the electronic medical record tools. Trainees across the globe who look for paper solutions are likely acculturated by existing embedded practices and the lure of the benefits of the paper work-around that outweigh the perceived downsides at their institutions. Regardless of the type of work-around adopted, the solutions required to go paperless lie in the minds of the tech-savvy house staff. We are not the first, nor will we be the last, to advocate for engaging these front-line users to develop EHR systems that support the realities of today's hospital work, but it is important enough to re-iterate time and again. These individuals-trainees who work at the front line and for whom paperless systems come more naturally than to their supervisors-can provide insight into electronic solutions not otherwise envisioned. These solutions paired with faster servers and processing speeds, and effective user interfaces will lay the foundation for paperless handovers. Until then, the pieces of paper are likely to endure.

The handover will always play many roles in hospital care. The gold standard approach to handover is face-to-face with exchange of both written and verbal information. Written and verbal complement each other and one cannot replace the other. Reading through the printed list (or, possibly, pulling it up on a screen) together in a space somewhat protected from distraction, interruption and competing tasks is vital for creating a shared mental model and unambiguous transfer of accountability from one provider or team to another. It also forces harried and distracted providers to pause and be mindful, individually and collectively. This meeting of minds may, in fact, improve clinical reasoning and diagnostic accuracy and is being considered the 'upside' of discontinuity. ${ }^{11}$ 
In summary, the study by Rosenbluth et al advances our understanding by highlighting a lesion in our handover systems - the printed handover document. We agree that printing the document is error-prone and suboptimal. We also agree that in today's information age, it should not be necessary. That said, we might not yet be ready to leave behind the printers. Are we Luddites advocating holding on to the past? Unlikely. We affirm the recommendation to look to the electronic record for the most accurate information to make clinical decisions. We also believe that before we confidentially recycle our folded pieces of paper, we must recognise that this seemingly simple change is mired in the complexity of the multiple roles that the handover document plays a shift from individuals to teams caring for patients, and IT infrastructures that do not optimally meet the needs of today's care delivery system. By analysing current work-flows through a systems lens and engaging providers at all levels to inform our understanding, we may be able to create the new and innovative tools required to support all the activities in our complex world of hospital care. These tools, combined with individual mindset and behaviour changes, are necessary. Hopefully then we can let the handover document fill its original purpose, to support a seamless transition at shift change, and finally we can move from paper to screen.

Competing interests None declared.

Provenance and peer review Commissioned; internally peer reviewed.

\section{REFERENCES}

1 The Joint Commission. Sentinel Event Data-Root Causes by Event Type (cited 26 October 2015). http://www.
jointcommission.org/assets/1/18/Root_Causes_Event_Type 2004-2Q_2015.pdf

2 ACGME Common Program Requirements (cited 26 October 2015). https://www.acgme.org/acgmeweb/Portals/0/PFAssets/ ProgramRequirements/CPRs_07012015.pdfhttp://www.acgme. org/acgmeweb/Portals/0/InstitutionalRequirements_07012014. pdf

3 Royal College of Physicians and Surgeons of Canada. The Draft 2015 CanMEDS Physician Competency Framework Series IV (cited 26 October 2015). http://www.royalcollege.ca/ portal/page/portal/rc/common/documents/canmeds/framework/ canmeds2015_framework_series_IV_e.pdf

4 Starmer AJ, Spector ND, Srivastava R, et al. Changes in medical errors after implementation of a handoff program. N Engl J Med 2014;371:1803-12.

5 Rosenbluth G, Jacolbia R, Milev D, et al. Half-life of a printed handoff document. BMJ Qual Saf 2016;25:324-8.

6 Petersen LA, Orav EJ, Teich JM, et al. Using a computerized sign-out program to improve continuity of inpatient care and prevent adverse events. Jt Comm J Qual Improv 1998;24:77-87.

7 Van Eaton EG, Horvath KD, Lober WB, et al. A randomized, controlled trial evaluating the impact of a computerized rounding and sign-out system on continuity of care and resident work hours. J Am Coll Surg 2005;200:538-45.

8 Sarkar U, Carter JT, Omachi TA, et al. SynopSIS: integrating physician sign-out with the electronic medical record. J Hosp Med 2007;2:336-42.

9 Li P, Ali S, Tang C, et al. Review of computerized physician handoff tools for improving the quality of patient care. J Hosp Med 2013;8:456-63.

10 Vidyarthi AR, Arora V, Schnipper JL, et al. Managing discontinuity in academic medical centers: strategies for a safe and effective resident sign-out. J Hosp Med 2006;1:257-66.

11 Yazici C, Abdelmalak H, Gupta S, et al. Sustainability and effectiveness of a quality improvement project to improve handoffs to night float residents in an internal medicine residency program. J Grad Med Educ 2013;5:303-8. 